\title{
Catalytic Function of Fish Muscle Extract in Linoleate Oxidation
}

\author{
Chiaki Kolzumi, ${ }^{*}$ Shun Wada, ${ }^{*}$ and Junsaku NonakA*
}

(Received December 25, 1975)

\begin{abstract}
The catalytic function of fish muscle extract in linoleate oxidation was examined and compared with those of metmyoglobin (metMb) and $\mathrm{FeSO}_{4}$ as catalyst. The muscle extracts of the four species of fishes examined, namely, big-eye tuna, yellowfin tuna, yellowtail, and sablefish, catalyzed the oxidation of linoleate, those of big-eye tuna and yellowfin tuna being more strongly catalytic than those of yellowtail and sablefish. The oxidation catalyzed by the muscle extract of big-eye tuna was enhanced by ascorbic acid and by cysteine but inhibited by EDTA, a catalytic feature resembling that of $\mathrm{FeSO}_{4}$. However, it could not be deduced that the non-heme iron is the main catalyst in the oxidation induced by the muscle extract since the oxidation catalyzed by the mixture of metMb and bovine serum albumin, which was developed by us as a model system suitable for hemoprotein catalysis, was also inhibited by EDTA. On the contrary, the results obtained with imidazole clearly indicated that the catalytic function of the muscle extract is due in large part to the presence of hemoprotein rather than non-heme iron; imidazole inhibited the oxidation catalyzed by both the muscle extract and metMb but did not influence that catalyzed by $\mathrm{FeSO}_{4}$.
\end{abstract}

Lipids in fish flesh are rich in highly unsaturated fatty acids responsible for oxidative rancidity. Hemoproteins, such as myoglobin $(\mathrm{Mb})$ and hemoglobin, and non-heme iron, which are powerful catalysts for unsaturated lipid oxidation, are widely distributed in fish flesh. On the other hand, some of the constituents of fish flesh such as some amino acids $^{1,2)}$ protect the unsaturated lipids from oxidation. It is therefore likely that the mechansims of lipid oxidation in fish flesh is complicated by the intervention of proand anti-oxidative constituents mentioned above.

LIU $^{3,4)}$ and LIU and WATTS ${ }^{\text {s) }}$ have demonstrated that both hemoprotein and nonheme iron contribute to the lipid oxidation in minced pork and beef. However, no information has been available on the lipid oxidation in fish flesh in this regard. For the purpose of studying the mechanism of lipid oxidation in fish ffesh, the effects of the fish muscle extract on the oxidation of unsaturated lipid were examined preliminarily.

This paper deals with the role and type of catalytic function of fish muscle extract in the oxidation of linoleate.

\section{Experimental}

Arginine linoleate Arginine linoleate, prepared after CHANG et al. ${ }^{6)}$, was used as a

* Tokyo University of Fisheries, 4-5-7 Konan, Minato-ku, Tokyo (小泉千秋・和田俊 - 野中順三九： 東京办産大学) 
substrate, since it is easily dispersed in acid phosphate buffer. Linoleic acid was obtained from Schwarze Mann and used without further purification. Arginine linoleate was dispersed in nitrogen saturated distilled deionized water just before use.

Tuna metMb Crystalline tuna metmyoglobin (metMb) was prepared from the dark muscle of big-eye tuna, Thunnus obesus, by the method of ScHMID. ${ }^{\text {") }}$

Muscle extract Fresh specimens of big-eye tuna, yellowfin tuna, Thunnus albacores, yellowtail, Seriola quiugueradiata, and sablefish, Anoploma fimbria, were purchased from a local fish store and used. A twenty gram portion of ordinary muscle excised from each fish was homogenized with $40 \mathrm{~m} l$ of $0.25 \mathrm{M}$ sucrose solution previously cooled in a refrigerator, filtered with four-fold gauze, centrifuged at $20,000 \mathrm{rpm}$ for $40 \mathrm{~min}$ at $5^{\circ} \mathrm{C}$, and filtered with filter paper. The filtrate was stored in a refrigerator and used after appropriate dilution with diluted sucrose solution $(0.25 \mathrm{M}$ sucrose: water, $2: 1)$. The muscle extract was freshly prepared daily. Concentrations of protein and $\mathrm{Mb}$ in the muscle extract were determined respectively by the method of LowRY et al. ${ }^{8)}$ using bovine serum albumin (BSA) as a standard and by the method of DRABKIN ${ }^{97}$ using 11.3 as millimolar extinction coefficient for metmyoglobin cyanide at $540 \mathrm{~nm}$. BSA was obtained from Nutritional Biochem. Co.

Method Rate of linoleate oxidation in $0.05 \mathrm{M}$ phosphate at $\mathrm{pH} 6.3$ and $5^{\circ} \mathrm{C}$ was determined in the same manner as reported previously ${ }^{10}$, using an oxygen electrode. The rate of oxidation was represented by a decrease in relative oxygen density of reaction system as in the previous paper.

\section{Results and Discussion}

Effect of muscle extract on linoleate oxidation Each muscle extract of the four fishes was added to the reaction system containing 1.5 or $2.0 \mathrm{~mm}$ linoleate after appropriate dilution and the rate of oxidation was determined. The results obtained are shown in Fig. 1.

The concentrations of total $\mathrm{Mb}$ and protein in the muscle extract of big-eye tuna were determined to be $40.8 \mu \mathrm{M}$ and $28.8 \mathrm{mg} / \mathrm{ml}$, respectively. When the extract was added to the reaction system to give $5 \mu \mathrm{M}$ of final concentration of $\mathrm{Mb}$ (protein: $3.52 \mathrm{mg} / \mathrm{m} l$ ), the oxygen consumption of the system occurred rapidly, as compared with that of the control which did not contain the linoleate. This clearly indicates that the linoleate undergoes the oxidation catalyzed by the muscle extract. The rate of oxidation was not influenced by decreasing the concentration of muscle extract in the system. With increasing concentration of the extract in the system (Mb: $7 \mu \mathrm{M}$, protein: $4.95 \mathrm{mg}$ / $\mathrm{ml}$ ), the rate of oxidation decreased to some extent.

Similar results were obtained with the muscle extract of yellowfin tuna, in which 


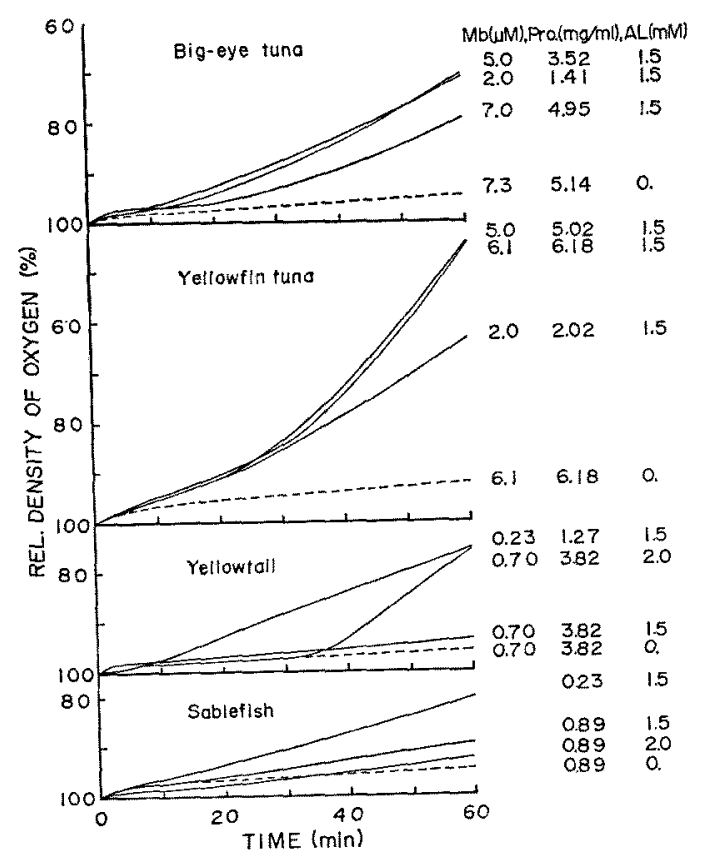

Fig. 1. Effects of the fish muscle extracts on the linoleate oxidation at $5^{\circ} \mathrm{C}$. Each system contained $1.5 \mathrm{~mm}$ arginine linoleate (AL) and the muscle extract in $0.05 \mathrm{M}$ phosphate at $\mathrm{pH} 6.3$. The concentrations of muscle extract in the system were indicated in the figure as those of $\mathrm{Mb}$ and protein (Pro.). The muscle extract of sablefish did not contained any measurable amount of $\mathrm{Mb}$.

the concentrations of total $\mathrm{Mb}$ and protein were $34.3 \mu \mathrm{M}$ and $34.6 \mathrm{mg} / \mathrm{m} /$, respectively.

The muscle extract of yellowtail, which contained $3.91 \mu \mathrm{M}$ of $\mathrm{Mb}$ and $21.4 \mathrm{mg} / \mathrm{m} l$ of protein, accelerated the oxidation of linoleate to some extent after appropriate dilution (Mb: $0.23 \mu \mathrm{M}$, protein: $1.27 \mathrm{mg} / \mathrm{ml}$ ). In the case of sablefish, the muscle extract contained no measurable quantity of $\mathrm{Mb}$ and relatively small amount of protein $(4.97 \mathrm{mg} / \mathrm{ml})$. However, it caused the catalytic oxidation of linoleate, although at a low rate.

From these results, it is obvious that the muscle extracts of these fishes, even that of sablefish which does not contain any measurable amount of $\mathrm{Mb}$, have a powerful catalytic function in the oxidation of linoleate. However, the rates of oxidation catalyzed by these muscle extracts were low, especially in the early stage of the reaction, as compared with that catalyzed by metMb at the same level, as shown in Fig. 2. This seems to indicate that the muscle extract has at least two different functions for the oxidation, that is, one is accelerative and the other inhibitory. From the fact that the catalytic effect of the extract of tuna muscle, which is tinged with red, is stronger than that of sablefish muscle which is visually white, the accelerative function 


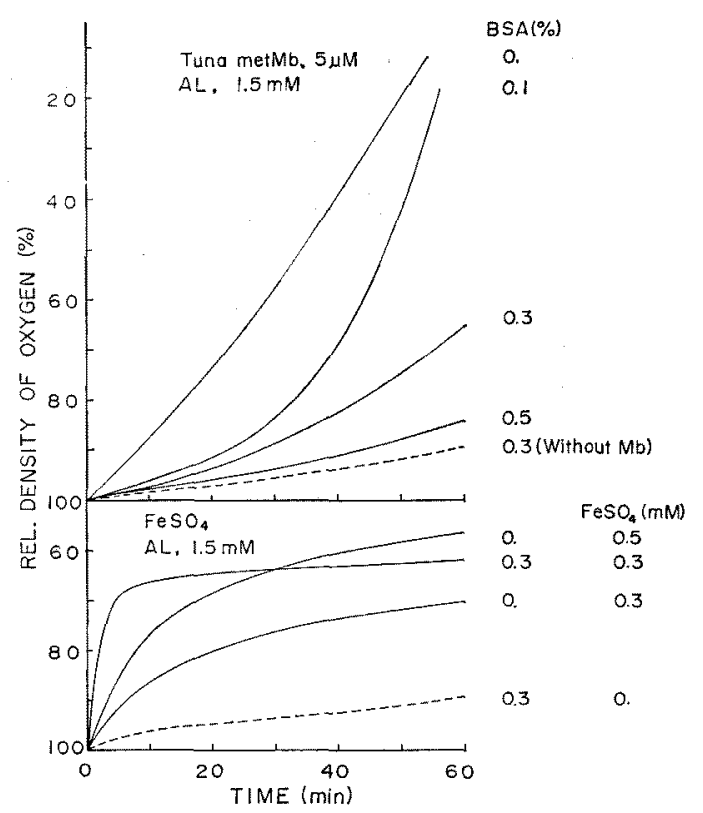

Fig. 2. Effect of BSA on metMb and $\mathrm{FeSO}_{4}$ catalyses at $5^{\circ} \mathrm{C}$. Each system contained $1.5 \mathrm{~mm}$ linoleate, catalyst, and BSA, where indicated in the figure, in $0.05 \mathrm{M}$ phosphate at pH 6.3 . Tuna metMb and $\mathrm{FeSO}_{4}$ were used as catalyst for hemoprotein and non-heme iron catalyses, respectively. The concentrations of catalysts and BSA were indicated in the figure.

of the muscle extract may be considered to be due in part to the presence of hemoprotein such as $\mathrm{Mb}$. Another factor may be non-heme iron as has been reported on pork and beef by LIU and WATTS ${ }^{5}$.

Effect of BSA on the rates of oxidation catalyzed by metMb and $\mathrm{FeSO}_{4}$ For the purpose of developing the model system suitable for studying the catalytic action of hemoprotein and non-heme iron, the effects of metMb and $\mathrm{FeSO}_{4}$ on the oxidation of linoleate were examined. The results obtained are shown in Fig. 2.

$\mathrm{MetMb}$ at a concentration of $5 \mu \mathrm{M}$ markedly accelerated the oxidation of linoleate $(1.5 \mathrm{~mm})$. The initial rate of oxidation was considerably higher than those catalyzed by the muscle extracts of big-eye tuna and yellowfin tuna at the same concentration of $\mathrm{Mb}$ (Fig. 1). When $0.1 \% \mathrm{BSA}$ was added to the reaction system before addition of metMb, the rate of oxidation decreased markedly in the early stage of the reaction. The rate of oxidation further decreased, as the concentration of BSA in the system increased. In the presence of $0.3 \%$ BSA, the catalyzed oxidation proceeded in a pattern similar to those catalyzed by the muscle extracts of fish.

$\mathrm{FeSO}_{4}$ at a concentration of 0.3 or $0.5 \mathrm{~mm}$ was a powerful catalyst in the oxidation of linoleate. The oxidation proceeded rapidly in the initial stage of the reaction. This 
catalytic feature was different from those of the muscle extracts. When BSA at a concentration of $0.3 \%$ was added to the system, the oxidation catalyzed by $0.3 \mathrm{~mm}$ $\mathrm{FeSO}_{4}$ was further accelerated in the first few minutes of the reaction. In the latter part of the reaction, the oxidation became slower than that of control which did not contain BSA.

WILLS ${ }^{11}$ has observed the accelerative effect of BSA on the oxidation of linoleate catalyzed by $\mathrm{Fe}^{3+}$ and ascorbate and presumed that the effect of BSA is due to increase in the stability of the linoleate emulsion. On the other hand, TAPPEL ${ }^{12}$ has studied the copper induced oxidation of linolate and stated that the effect of BSA is a result of the binding of copper by the protein.

On the basis of the results obtained above, the following model system were used for the comprison of catalytic function of the muscle extract of fish with those of hemoprotein and non-heme iron: the model for hemoprotein catalysis consisting of $1.5 \mathrm{mM}$ linoleate, $0.3 \% \mathrm{BSA}$, and $5 \mu \mathrm{M}$ tuna metMb in $0.05 \mathrm{M}$ phosphate, $\mathrm{pH} 6.3$, and that for
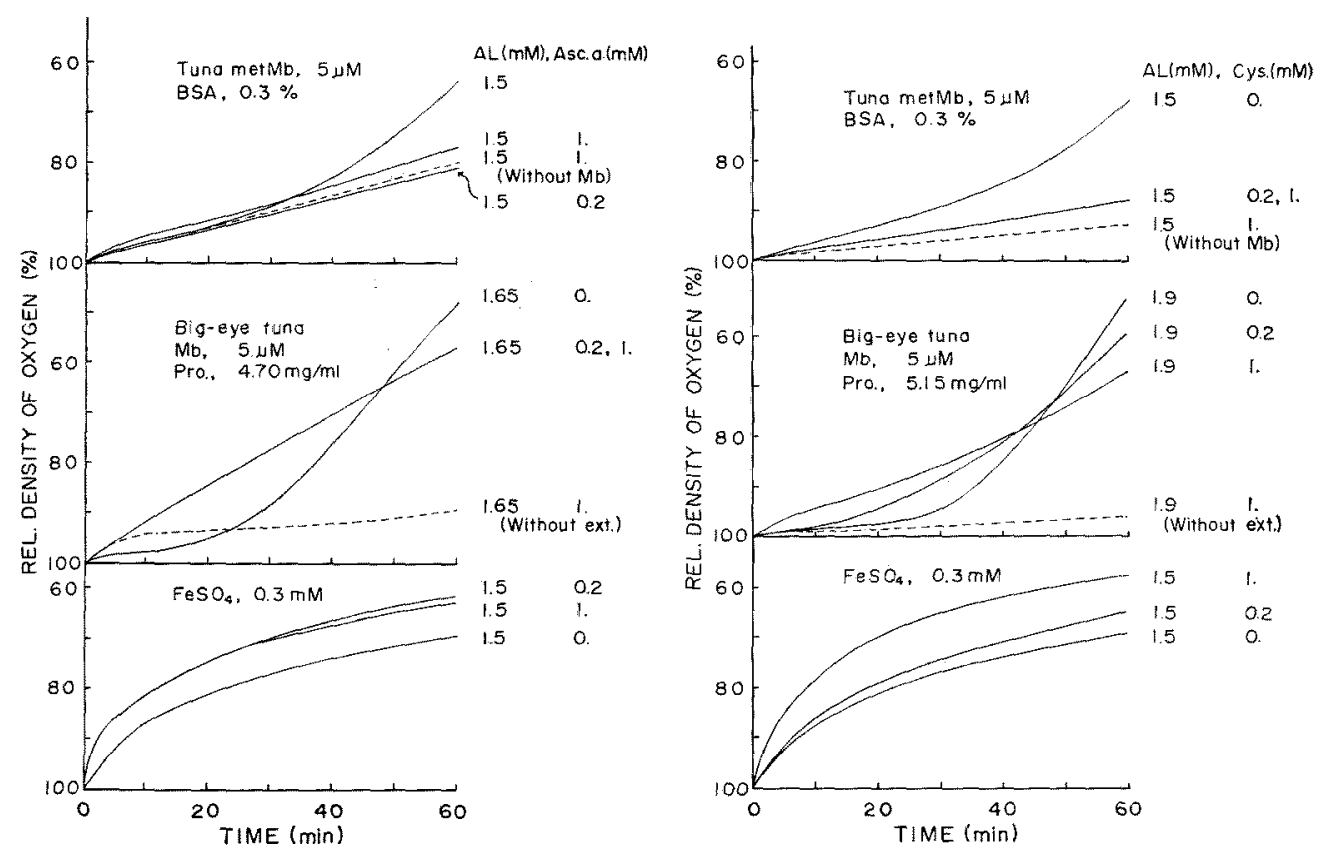

Fig. 3. Comparison of the catalysis of muscle extract with those of metMb and $\mathrm{FeSO}_{4}$ in the presence of ascorbic acid (Asc. a.). The reactants and their concentrations in the system were indicated in the figure. Unless otherwise stated, the reaction was performed in $0.05 \mathrm{M}$ phosphate at $\mathrm{pH} 6.3$ and $5^{\circ} \mathrm{C}$,

Fig. 4. Comparison of the catalysis of muscle extract with those of metMb and $\mathrm{FeSO}_{4}$ in the presence of cysteine (Cys.). The reactants and their concentrations in the system were indicated in the figure. 
non-heme iron catalysis consisting of $1.5 \mathrm{~mm}$ linoleate and $0.3 \mathrm{mM} \mathrm{FeSO}_{4}$ in the same buffer.

Effects of reducing agents It is generally accepted that reducing agents such as ascorbic acid and cysteine strongly inhibit the oxidation catalyzed by metMb but accelerate that catalyzed by non-heme iron. The oxidation catalyzed by the muscle extract of big-eye tuna was studied in this regard. The results obtained with ascorbic acid and cysteine are shown in Figs. 3 and 4, respectively.

The muscle extract accelerated markedly the oxidation of $1.65 \mathrm{~mm}$ linoleate after an induction period. When ascorbic acid was added to the reaction system to give a final concentration of 0.2 or $1 \mathrm{mM}$ before initiation of the reaction, the oxidation was accelerated in the early stage of the reaction and the induction period disappeared.

In the case of metMb catalyzed oxidation, ascorbic acid at the same concentration inhibited almost completely the oxidation of linoleate. Contrary to this, the oxidation catalyzed by $\mathrm{FeSO}_{4}$ was further accelerated in the initial stage of the reaction by adding 0.2 or $1 \mathrm{~mm}$ ascorbic acid to the system.

Similar results were obtained with cysteine as can be seen in Fig. 4.

These results suggest that the catalytic function of the muscle extract in the oxidation

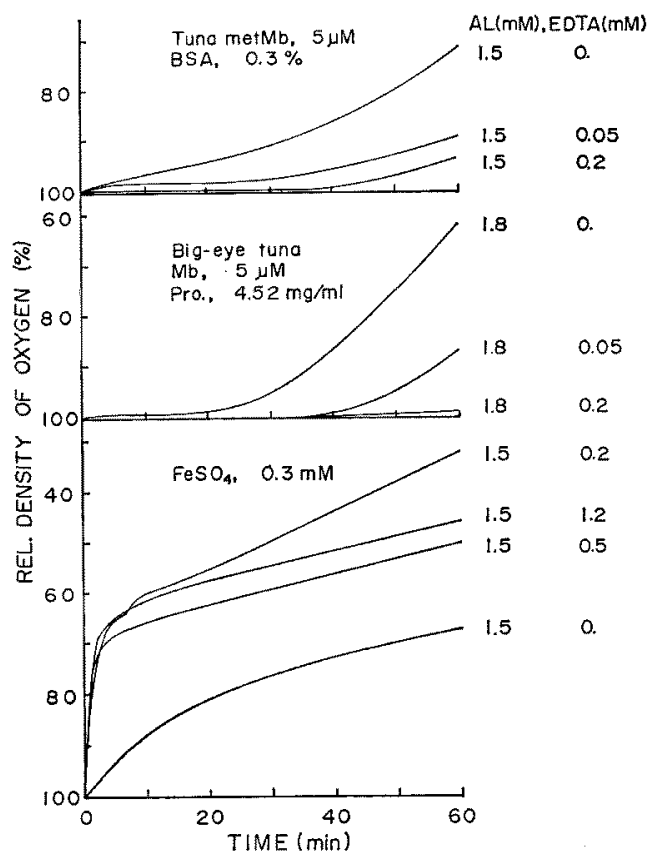

Fig. 5. Comparison of the catalysis of muscle extract with those of metMb and $\mathrm{FeSO}_{4}$ in the presence of EDTA. The reactants and their concentrations in the system were indicated in the figure. 
may be due in part to non-heme iron components.

Effect of EDTA It has been reported that EDTA has no effect on hemoprotein catalysis but exerts certain complicated influences on non-heme iron catalysis, that is, EDTA acts as an accelerator at lower concentration ratio of EDTA to iron as a catalyst, while it acts as an inhibitor at a higher concentration ratio. ${ }^{8,13}$

Effects of EDTA on the oxidation catalyzed by the muscle extract, metMb, and $\mathrm{FeSO}_{4}$ were compared. The results obtained are shown in Fig. 5. When EDTA was added to the reaction system to give a final concentration of $0.05 \mathrm{~mm}$, the oxidation catalyzed by the muscle extract was strongly inhibited accompanied by the production of an induction period. With increasing concentration of EDTA, the oxidation was completely inhibited. This seems to be indicative of the contribution of non-heme iron in the oxidation induced by the muscle extract. However, the oxidation catalyzed by metMb was also inhibited by adding $0.05 \mathrm{mM}$ EDTA to the system. With incrasing concentration of EDTA, the inhibitory effect was intensified and the induction period was prolonged. This strong inhibitory effect of EDTA on the metMb catalysis may be due to coexistence with BSA in the reaction system, since EDTA had no effect on the catalyzed oxidation of linoleate in the system to which BSA was not added. It must be emphasized that the effect of EDTA on the metMb catalysis depends on the reaction conditions used; EDTA inhibits not only non-heme iron catalysis, as has been accepted in general, but also the hemoprotein catalysis under some conditions. From

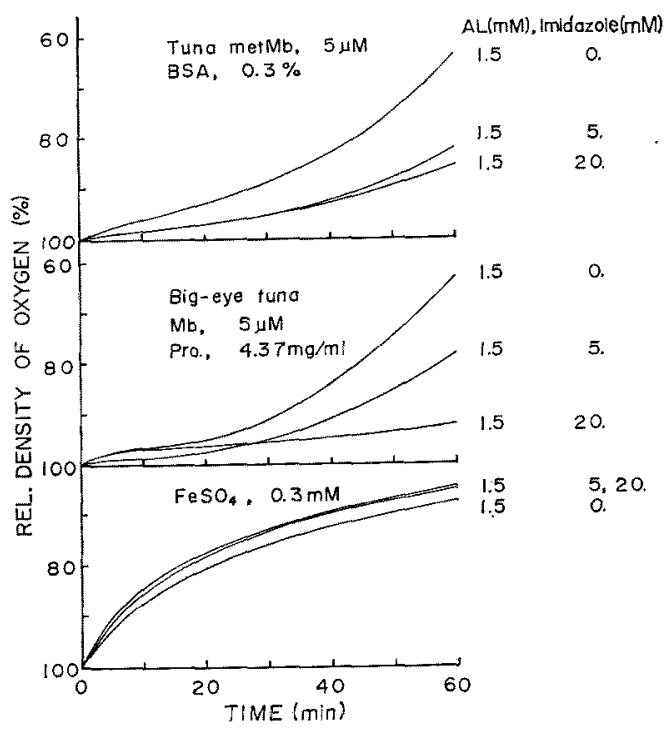

Fig. 6. Comparison of the catalysis of muscle extract with those of metMb and $\mathrm{FeSO}_{4}$ in the presence of imidazole. The reactants and their concentrations in the system were indicated in the figure. 
these results, it could not be deduced that the catalytic function of the muscle extract in the linoleate oxidation was due to the presence of non-heme iron.

In the case of the oxidation catalyzed by $\mathrm{FeSO}_{4}$, EDTA at the lower concentration used $(0.2 \mathrm{mM})$ markedly accelerated the oxidation of linoleate, especially in the initial stage of the reaction. With increasing concentration of EDTA in the system, the accelerative effect became weak. However, even at a concentration as high as $1.2 \mathrm{mM}$, EDTA accelerated the oxidation. This differs from the results reported so far that EDTA at higher concentrations inhibits non-heme iron catalysis. The effect of further increased concentration of EDTA was not studied. This disagreement may be attributed to the experimental procedure used in the present study, in which the oxidation was initiated by adding $\mathrm{FeSO}_{4}$ to the reaction system consisting of linoleate and EDTA; the oxidation may have commenced before $\mathrm{FeSO}_{4}$ reacted completely with EDTA to form their complex.

Effect of imidazole As previously reported, imidazole inhibits the oxidation of linoleate catalyzed by both metMb and $\mathrm{MbO}_{2}{ }^{10)}$. Effect of imidazole at concentrations of 5 and $20 \mathrm{~mm}$ were studied on the catalyzed oxidation. The results obtained are shown in Fig. 6.

When $5 \mathrm{~mm}$ imidazole was added to the system before initiation of the reaction, the oxidation of linoleate catalyzed by the muscle extract was inhibited to some extent. With increasing concentration of imidazole in the system, the inhibitory effect increased. The oxidation catalyzed by metMb was also inhibited by 5 or $20 \mathrm{~mm}$ imidazole. As can be seen in Fig. 6 , in the presence of $5 \mathrm{~mm}$ imidazole the oxidation pattern in the catalysis with the muscle extract resembled closely that of metMb.

On the other hand, imidazole at the same concentration was ineffective on the oxidation catalyzed by $\mathrm{FeSO}_{4}$. These results strongly suggest that the catalytic function of muscle extract of fish in linoleate oxidation is caused by the hemoprotein. No evidence was obtained to indicate that non-heme iron contributed significantly to the oxidation catalyzed by the muscle extract.

In conclusion, hemoprotein such as $\mathrm{Mb}$ may play a major role as a catalyst in the oxidation accelerated by the muscle extract of big-eye tuna. However, the role of non-heme iron is also undeniable, as can be seen in the results of the experiment using reducing agents.

This work was partly supported by a grant from the Ministry of Education. 


\section{References}

1) R. Marcuse: J. Am. Oil Chemist's Soc., 39, 97-103 (1962).

2) C. H. Castell, J. Maclean, B. Moore, and W. Neal: J. Fish. Res. Bd. Canada, 23, 27-43 (1966).

3) Hsiao-Ping Liu: J. Food Sci., 35, 590-592 (1970).

4) Hslao-Ping Lu: ibid., 35, 593-595 (1970).

5) Hsiao-Ptng Liu and B. M. Watts: ibid., 35, 596-598 (1970).

6) R. W. Chang, S. Paul, and F. L. Moyer: U. S. Patent 2,945,049 (1960).

7) K. SCHMm: Helv. Chim. Acta, 32, 105-114 (1949).

8) O. H. Lowry, N. J. Rosebrough, A. L. Farr, and R. J. Randall: J. Biol. Chem., 193, 265-275 (1951).

9) D. L. Drabkin: Am. J. Med. Sci., 209, 268-270 (1945).

10) C. KolzumI and J. NonaKa: This Bull., 41, 1053-1061 (1975).

11) E. D. WiILs: Biochim. Biophys. Acta, 98, 238-251 (1965).

12) A. L. TappeL: J. Am. Oil Chemist's Soc., 32, 2\$2-254 (1955).

13) A. A. Barber: Lipids, 1, 146-151 (1966). 